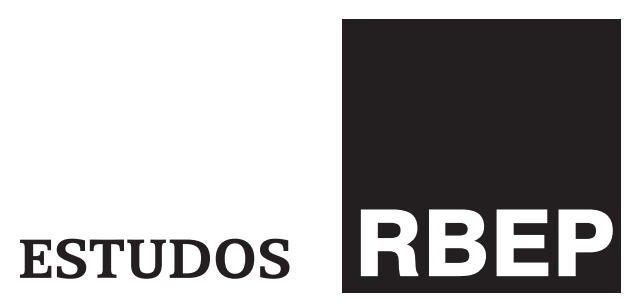

\title{
Alunos cotistas e atividades extracurriculares: análise do Censo da Educação Superior 2009
}

Rodrigo Travitzki

Rafael Luís Galdini Raimundo

\section{Resumo}

Avalia o grau de inclusão de alunos cotistas e não cotistas na vida acadêmica a partir da análise das atividades extracurriculares realizadas por 5.579.406 alunos incluídos no Censo da Educação Superior de 2009. A média de atividades extracurriculares realizada por alunos cotistas (X $=0,28$ ) foi maior que a média dos alunos não cotistas $(X=0,17)$ depois de dois anos dentro da Instituição de Ensino Superior (IES). Ao longo de seus cursos, os alunos cotistas também acumularam mais atividades remuneradas e não remuneradas nas categorias de estágio, monitoria, pesquisa e extensão. Os resultados aqui apresentados corroboram a hipótese de que as cotas proporcionaram inclusão com qualidade, contudo, são evidências a favor da ação afirmativa no ensino superior de um modo geral, não necessariamente do modelo de cotas adotado pela maioria das IES brasileiras.

Palavras-chave: ação afirmativa; sistema de cotas; estatística da educação; inclusão educacional; censo da educação superior. 


\section{Abstract \\ Students selected under quotas and extracurricular activities: analysis of the Higher Education Census 2009}

This article evaluates the degree of inclusion of students selected for affirmative action program quotas, and those not under quotas in the academic life, by analyzing the extracurricular activities developed by 5,579,406 students recorded in the Brazilian 2009 Higher Education Census. The average extracurricular activities performed by students selected under affirmative action programs $(X=0.28)$ was higher than other students $(X=0.17)$ after a two-year period in the Higher Education Institution (IES). During their courses, the students under the quota also accumulated more remunerated and non-remunerated activities related to internship, teaching, research and extension. The results presented here support that the affirmative action program quotas provide quality inclusion in a broad sense. However, they are also evidence that this is not applied to the model of program quotas followed and used by most Brazilian Higher Education Institutions.

Keywords: affirmative action; quota system; statistical education; educational inclusion; higher education census.

\section{Objetivo}

O sistema de cotas na educação superior brasileira continua sendo um tema bastante polêmico e suscita debates em diferentes campos do saber, desde a filosofia (exempli gratia o significado do princípio da igualdade em um mundo essencialmente desigual) até a economia (exempli gratia o uso eficaz dos recursos públicos). Uma das polêmicas mais comuns é a polarização "inclusão versus qualidade": de um lado, alguns argumentam que destinar uma porcentagem de vagas a grupos socialmente excluídos leva a uma queda de qualidade nas atividades de ensino, pesquisa e extensão; alternativamente, outros consideram que há um grande contingente de talentos ocultos nos grupos excluídos que, em virtude de aspectos estruturais da sociedade brasileira, não conseguem realizar plenamente suas potencialidades - nem para si, nem para a sociedade. Em consequência, uma política de inclusão eficiente poderia promover a melhoria da qualidade das universidades brasileiras.

Em casos como esse, em que argumentos opostos podem soar igualmente consistentes, a avaliação dos resultados da política pública em termos empíricos é um imperativo. No entanto, poucas informações quantitativas estão disponíveis para embasar uma análise mais aprofundada sobre os impactos do sistema de cotas que começou a ser implantado 
nas universidades brasileiras em 2005. Alguns estudos foram feitos com base nos dados da Pesquisa Nacional por Amostra de Domicílios (Pnad), mas outras fontes de informação, como o Censo da Educação Superior (CES), permanecem subexploradas.

Diante de tal contexto, o trabalho aqui apresentado teve como objetivo investigar se existem diferenças entre cotistas e não cotistas no que se refere à realização de atividades extracurriculares nas Instituições de Ensino Superior (IES), o que foi tomado como um indicador da inserção dos alunos na vida acadêmica.

\section{Introdução}

O conceito de ação afirmativa originou-se nos Estados Unidos, em meados do século passado, num contexto de reivindicações democráticas de igualdade de oportunidade a todos. Mais especificamente em 1965, quando o presidente dos Estados Unidos, Lyndon Johnson, convidou os cidadãos a "tomarem ações afirmativas para garantir que candidatos sejam empregados e uma vez empregados sejam tratados igualmente, independentemente de sua raça" (Tessler, 2006). Na Europa, a ideia começou a surtir efeito em 1976, frequentemente sob a expressão de "ação ou discriminação positiva" (Moehlecke, 2002). Desde então, multiplicaram-se os estudos sobre o tema, muitos deles com abordagem unilateral e dicotômica, polarizada, por exemplo, entre a "ação afirmativa como alternativa de promoção de justiça social e reparação histórica de efeitos discriminatórios" e os "questionamentos sobre a incumbência estatal para esse tipo de política pública" (Guarnieri; Melo-Silva, 2007). Mas, afinal, qual é o significado desse conceito?

A ação afirmativa estaria ligada a sociedades democráticas, que tenham no mérito individual e na igualdade de oportunidades seus principais valores. Desse modo, ela surge 'como aprimoramento jurídico de uma sociedade cujas normas e mores pautam-se pelo princípio da igualdade de oportunidades na competição entre indivíduos livres', justificando-se a desigualdade de tratamento no acesso aos bens e aos meios apenas como forma de restituir tal igualdade, devendo, por isso, tal ação ter caráter temporário dentro de um âmbito e escopo restritos (Moehlecke, 2002).

Na educação brasileira, um marco recente nas políticas de ação afirmativa foi a Lei $n^{\circ}$ 10.558/2002 (Brasil, 2002), que criou o Programa Diversidade na Universidade (Produ), regulamentado pelo Decreto $n^{\circ}$ 4.876/2003 (Brasil, 2003). O Produ tem como objetivo "implementar e avaliar estratégias para a promoção do acesso ao ensino superior de pessoas pertencentes a grupos socialmente desfavorecidos" (Brasil, 2002), mediante a transferência de recursos federais para entidades públicas ou privadas. Isso estimulou as instituições a elaborarem seus próprios sistemas de ação afirmativa na passagem entre o ensino médio e o ensino superior, onde há um estreito gargalo na igualdade de oportunidades (Neves; Raizer; Fachinetto, 2007).

Em parte, essa nova estratégia política pode ser explicada pelo histórico de estruturação da rede de IES brasileira ao longo dos últimos 40 anos. 
Até a década de 1970, as IES brasileiras vinham crescendo gradualmente, mas depois disso a ampliação da rede se estagnou por quase 30 anos. A Constituição de 1988, embora garantisse direitos às minorias, foi implementada num contexto de crise econômica e os recursos destinados à ciência e tecnologia (C\&T) e às IES eram bastante reduzidos (Corbucci, 2004). Em meados da década de 1990, com a falta de investimentos e a desregulamentação do setor, as instituições privadas entraram em cena e cresceram rapidamente. Para controlar a qualidade do serviço prestado foram elaborados exames como o Provão, mas, na prática, as instituições autorizadas inicialmente a funcionar continuaram suas atividades mesmo depois de comprovada sua baixa qualidade.

\begin{abstract}
Uma das implicações desse modelo de expansão adotado é que, atualmente, caminha-se para certo nível de saturação desse mercado, a qual fica evidenciada não apenas pela baixa taxa de ocupação das vagas ofertadas pela iniciativa privada, mas também pelos altos índices de inadimplência (Corbucci, 2004).
\end{abstract}

Nesse contexto de saturação do mercado das IES privadas, o Programa Universidade para Todos (ProUni) surgiria como uma política de transferência de renda para estimular o crescimento do ensino superior - embora existam críticas à sua eficácia enquanto mecanismo de democratização (Catani; Hey; Gilioli, 2006). As cotas nas instituições privadas aparecem muitas vezes vinculadas ao ProUni, enquanto nas instituições públicas podem servir para múltiplos objetivos, desde a inclusão social em si até a busca por maior qualidade nas diferentes atividades acadêmicas (Tessler, 2006).

A primeira instituição a coletar dados sobre a cor da pele dos candidatos foi a Universidade Federal da Bahia (UFBA), em 1998 (Santos; Queiroz, 2005). Segundo os autores, o sistema de cotas adotado, em 2005, mudou o perfil dos alunos, mas não a nota de corte, o que sugere uma política de inclusão com qualidade. A primeira universidade federal a adotar sistema de cotas raciais foi a Universidade de Brasília (UnB), no segundo semestre de 2004 (Maio; Santos, 2005). Embora as cotas raciais sejam muito discutidas na mídia e nos pequenos círculos, a maioria dos modelos adotados privilegia, de fato, a reserva para alunos de escolas públicas (Brasil, Inep, 2010).

A Tabela 1 mostra os modelos de cotas adotados em 2005 pelas IES públicas, conforme dados da Assessoria de Comunicação Social (ACS) do Ministério da Educação. Na época, a maior parte dos modelos priorizava a inclusão de alunos negros ou daqueles que estudaram na rede pública. As cotas para pessoas portadoras de deficiência e para os indígenas também eram comuns, embora com porcentagens menores, e as cotas socioeconômicas, por sua vez, eram raras. A pluralidade de modelos implantados inicialmente pelas IES públicas revela uma diversidade de contextos e pressupostos amparados no princípio da autonomia universitária. Por outro lado, todos esses modelos tinham em comum a reserva de uma porcentagem predeterminada das vagas para um grupo considerado mais injustiçado. 
Tabela 1 - Primeiros Modelos de Cotas Adotados por IES Públicas em 2005

\begin{tabular}{|c|c|c|c|}
\hline IES & $\begin{array}{l}\text { Cotas total } \\
\qquad \begin{array}{c}(\mathrm{A})^{(1)} \\
(\mathrm{em} \%)\end{array}\end{array}$ & $\begin{array}{c}\text { Critério } \\
\text { global }^{(2)} \\
(\text { relativo à A) }\end{array}$ & $\begin{array}{l}\text { Modelo adotado(3) } \\
\text { (\% - Tipo) }\end{array}$ \\
\hline UERJ & 45 & $\mathrm{EP}$ & 20-EP; 20-EP+N; 5-EP+D/I \\
\hline UENF & 45 & não tem & 20-EP; 20-N; 5-D/I \\
\hline UEMG & 45 & não tem & 20-EP; 20-N; 5-D/I \\
\hline UFJF & 16 & $\mathrm{~N}$ & $16-\mathrm{N}$ \\
\hline UNIFESP & 10 & $\mathrm{EP}+\mathrm{N} / \mathrm{I}$ & $10-\mathrm{EP}+\mathrm{N} / \mathrm{I}$ \\
\hline UEA & - & $\mathrm{R} ; \mathrm{I}$ & - \\
\hline UFT & 5 & I & $5-\mathrm{I}$ \\
\hline UnB & 20 & $\mathrm{~N}$ & $20-\mathrm{N}$ \\
\hline ESCS-DF & 40 & $\mathrm{EP}$ & 40-EP \\
\hline UEMS & 25 & não tem & $20-N ; 5-I$ \\
\hline UFAL & 20 & $\mathrm{~N}$ & $12-\mathrm{N}+\mathrm{M} ; 8-\mathrm{N}+\mathrm{H}$ \\
\hline UFBA & 43 & não tem & 36-N+EP; 7-EP/I \\
\hline UNEB & 40 & $\mathrm{EP}+\mathrm{N} / \mathrm{P}$ & $\begin{array}{l}\text { 10-EP+N/P; } \\
20-E P+N / P+R .2 ; 10-E P+N / P+R .1\end{array}$ \\
\hline UFPR & 50 & não tem & 20-N; 20-EP; 5-D; 5-I \\
\hline UEL & 40 & não tem & 20-N; 20-EP \\
\hline
\end{tabular}

Fonte: Assessoria de Comunicação Social/MEC.

Notas: $(1)-$ Cotas total $=$ porcentagem total de vagas destinadas a cotas

(2) - Critério global $=$ tipo de cota

(3) - Modelo adotado $=$ síntese do esquema adotado

Legenda: $\mathrm{EP}=$ escola pública $\mid \mathrm{N}=$ negros $\mid \mathrm{P}=$ pardos $\mid \mathrm{I}=$ indígenas $\mid \mathrm{D}=$ deficientes $\mid \mathrm{M}=$ mulher $\mid \mathrm{H}=$ homem $\mid \mathrm{R}=$ renda $\mid$ R. $1=$ Renda até 1 salário mínimo $\left|(+)=" \mathrm{E}^{\prime \prime}\right|(/)=$ "OU" $\mid$ (;) = separa diferentes critérios.

Em poucos anos, as cotas se espalharam pelo País, como revelou o mapa das ações afirmativas elaborado pelo Laboratório de Políticas Públicas da Universidade Estadual do Rio de Janeiro (Uerj/LPP, 2008). O mesmo estudo mostrou o surgimento de um sistema alternativo ao das cotas, que ficou conhecido como sistema de bônus. Enquanto as cotas reservam um percentual fixo para determinado grupo social, o bônus apenas adiciona alguns pontos extras à nota do vestibular do aluno que se enquadre em determinado grupo, de forma que a proporção de beneficiados possa variar a cada ano de acordo com o mérito.

Uma das instituições a adotar o sistema de bônus foi a Universidade Estadual de Campinas (Unicamp), que em 2005 implementou o Programa de Ações Afirmativas e Inclusão Social (Paais). Segundo o ex-coordenador da Comissão Permanente para os Vestibulares da Unicamp (Comvest), Leandro Tessler, os principais objetivos do programa estão relacionados à excelência acadêmica, e não apenas aos princípios de igualdade e de inclusão.

A comunidade universitária percebeu nas discussões que com um programa bem pensado seria possível aliar inclusão social e mérito acadêmico. Adicionando pontos de bônus pode-se, de certa forma, 
compensar a diferença de pontuação obtida por indivíduos com diferentes histórias de vida, mas mérito semelhante, ao passarem pelo processo do vestibular (Tessler, 2006).

Um dos principais objetivos do programa foi estimular os alunos de escolas públicas a candidatarem-se, pois apenas 30\% dos candidatos da Unicamp vinham de escolas públicas, enquanto na sociedade eles representavam 80\% dos alunos. Segundo o ex-coordenador, desde 1987 o vestibular da Unicamp adota o modelo de questões dissertativas e redação, que conseguiu equilibrar a proporção entre alunos de escola pública que se candidataram e aqueles que efetivamente entraram (o modelo anterior, de testes, privilegiava alunos de escolas particulares). Assim, constatou-se que o principal problema não era que os estudantes da rede pública tinham baixo desempenho na prova, mas que, de fato, eles nem chegavam a inscrever-se no exame. O bônus, nesse contexto, veio como um estímulo para reverter o quadro.

O exemplo da Unicamp mostra como as ações afirmativas podem (e precisam) ir muito além das cotas, articulando diversas estratégias em diferentes dimensões, ou seja, não basta mudar a pontuação da prova, é preciso mudar o tipo de prova. Para reforçar o modelo, em 2000 a universidade começou a oferecer isenção da taxa de inscrição utilizando critérios socioeconômicos. O sistema de bônus do Paais, por sua vez, dá 30 pontos para quem veio de escola pública e mais 10 pontos para negros, pardos e indígenas, entretanto, o objetivo desses 10 pontos não seria simplesmente compensar uma injustiça histórica, tal qual nas ações afirmativas, o pressuposto do modelo adotado pela Unicamp é que "ao privilegiar o ingresso de autodeclarados pretos, pardos e indígenas criamos um ambiente de melhor qualidade para a formação de nossos estudantes" (Tessler, 2006).

A concepção do Paais partiu da "hipótese que em média os estudantes oriundos de escola pública melhorariam seu desempenho em relação ao vestibular mais do que os demais estudantes ao longo de seus cursos de graduação" (Tessler, 2006), o que justificaria o estímulo à sua participação. O ex-coordenador do vestibular da Unicamp considera que os resultados do estudo publicado em 2006 confirmam tal hipótese, pois em 95\% dos cursos os beneficiados pelo Paais melhoraram mais suas notas do que os outros. No concorrido curso de Medicina, "com o advento do Paais, o número de matriculados egressos de escolas públicas passou de 10 (9,1\%) em 2004 para 34 (31,0\%) em 2005 e 19 (17,3\%) em 2006" (Tessler, 2006). Para as pessoas que poderiam ter receio de serem tratadas por um "médico cotista", supondo um profissional menos qualificado, o estudo da Unicamp revelou que, em 34 dos 56 cursos, os cotistas apresentaram desempenho acadêmico superior aos alunos não cotistas, o que evidencia o sucesso do programa em conciliar inclusão com qualidade. Por fim, acrescenta Tessler, a proporção de estudantes negros, pardos, indígenas e vindos de escola pública atingiu os maiores índices da história da Unicamp em virtude do programa.

Neste trabalho, investigou-se a hipótese de que inclusão com qualidade, conforme estudos focalizados na UFBA (Santos; Queiroz, 2005) 
e na Unicamp (Tessler, 2006), pode ser generalizada nacionalmente. Como não existem informações padronizadas recentes de desempenho acadêmico (notas) para as IES brasileiras, foi construído um indicador de inclusão acadêmica baseado nas atividades extracurriculares de cada aluno, conforme registros do CES. Especificamente, buscou-se avaliar em que medida as políticas de cota implementadas desde 2005 têm permitido a entrada de jovens que integram-se à vida acadêmica, inserindo-se amplamente nas atividades de ensino, pesquisa e extensão.

\section{Fonte de dados e métodos}

Os dados do CES de 2009 (Brasil, Inep, 2011) foram utilizados para investigar a inserção de cotistas e não cotistas nas diferentes atividades acadêmicas. O Censo é uma das poucas bases com dados sobre o ensino superior com periodicidade anual e abrangência nacional, mas, até onde sabemos, ainda não foi utilizado para estudos sobre o impacto das políticas de ações afirmativas. Dos diversos conjuntos de dados disponíveis na base do CES, utilizamos apenas o conjunto "Alunos". Os dados originais foram lidos no programa Statistical Package for the Social Sciences (SPSS) e exportados no formato Comma-separated values (CSV), possibilitando assim sua importação para o $\mathrm{R}$, um ambiente de trabalhado baseado em software livre de reconhecida excelência, multiplataforma, bastante flexível e com a possibilidade de construção de pacotes específicos para diversos tipos de análises estatísticas.

Iniciamos com uma limpeza dos dados desnecessários e contraditórios. Da amostra inicial de 6.982.018 registros individuais, foram retirados os 996.145 alunos que não estavam em situação de matrícula. Detectamos então 32.624 registros em que os estudantes seriam simultaneamente formandos e ingressantes - retiramos esses dados. Levando em conta o objetivo de avaliar os efeitos das ações afirmativas, excluímos os 373.843 registros de matrículas anteriores a 2005, ano em que tais políticas se implementaram no Brasil. Ao final do processo de limpeza restou, portanto, uma amostra de 5.579.406 registros.

Em caráter exploratório, os dados foram agrupados e totalizados para obtenção do perfil geral dos estudantes (percentuais de homens e mulheres, a idade, a cor, os portadores de deficiência e os estrangeiros), tipo de financiamento (reembolsável e não reembolsável), bem como dos percentuais em cada tipo de cota. Ainda como parte da análise exploratória dos dados, calculou-se a matriz de correlação de Pearson entre as variáveis numéricas (incluindo as binárias, com $\operatorname{sim}=1$ e não $=0$ ) da amostra. Destacamos a seguir as mais significativas, que atingiram um mínimo de 0,1 (todas com $p<0,001$ ).

Para a construção do indicador de inclusão dos alunos nas atividades acadêmicas foram utilizadas oito variáveis binárias $(0 / 1)$ da seção "Atividade de Formação Complementar", referindo-se à realização ou não de: a) pesquisa; b) monitoria; c) estágio; e d) extensão. Cada qual 
subdividida em duas possibilidades: remunerada ou não remunerada. Essas oito variáveis foram agrupadas e somadas, gerando sete indicadores, o principal deles, síntese de todos os outros, variou de 0 a 4 para cada aluno. Os outros seis indicadores são mais específicos, sendo quatro para cada tipo de atividade extracurricular e dois relativos à remuneração (ou não) das atividades.

A pontuação em cada um dos indicadores foi computada para alunos cotistas e não cotistas, considerando-se como variável interferente o tempo decorrido desde a matrícula, partindo-se da hipótese de que os cotistas tendem a melhorar mais rápido do que o restante, confirmada no estudo da Unicamp (Tessler, 2006).

De forma semelhante, todos os campos referentes a cotas (que podem ser étnicas, para escola pública, etc.) foram agrupados em uma variável do tipo sim ou não. Não foi possível realizar uma comparação significativa entre os tipos de cota, porque os dados provenientes de universidades públicas não apresentavam, em sua grande maioria, essa informação.

Por fim, estavam disponíveis três tipos de informação para análise: 1) se o aluno ingressou por cotas ou não (variável explanatória); 2) atividades extracurriculares que ele realizou na IES (variável resposta); 3) fatores possivelmente correlacionados (variáveis interferentes) que podem alterar a relação dos dois primeiros - a idade do aluno, o gênero, a raça, o ano de matrícula e o tipo de IES (pública ou privada).

Para testar a hipótese da inclusão com qualidade, os alunos foram agrupados segundo o ano de matrícula e então calculou-se a média de atividades extracurriculares totais de cada grupo. Ao plotar esses resultados, ficou evidente que a média de atividades extracurriculares dos cotistas crescia mais rápido do que no resto da amostra. Faltava, então, verificar se essa diferença nas médias era significativa. Com tal objetivo, foram retirados os alunos com menos de dois anos completos dentro da universidade - considerado tempo de "adaptação" dos cotistas ao ambiente acadêmico. A comparação das médias foi realizada por meio do teste não paramétrico de Wilcoxon (unicaudal). Como procedimento complementar, foram elaborados gráficos semelhantes ao descrito anteriormente, mas separados por subgrupos para verificar em que medida o padrão encontrado depende de outras variáveis.

Com o objetivo de contribuir para o desenvolvimento de metodologias públicas de análise estatística dos dados oficiais brasileiros, optamos pela utilização do programa R, já descrito anteriormente. Há, por exemplo, um grupo de pacotes para o R desenvolvido especialmente para análise do censo dos EUA, chamado Uscensus2000 (Almquist, 2010). Esse tipo de iniciativa potencializa a capacidade de produção cientifica coletiva, transparente e direcionada para aprimorar as políticas e as instituições democráticas, que precisam sempre de evidências e de informações minimamente confiáveis. Trabalhando nessa linha, disponibilizaremos os arquivos para $\mathrm{R}$ na internet. Com pequenas mudanças, o script elaborado para este trabalho poderá ser utilizado em versões posteriores do CES, caso o formato dos dados seja mantido. 


\section{Resultados}

A amostra de 5.579.406 estudantes dividiu-se desigualmente entre os sexos, com 2.354.173 (42,2\%) homens e 3.225 .233 (57,8\%) mulheres - a idade média foi de 26,7 anos (DP = 8,1). É curioso notar que, no País da miscigenação, a maioria dos alunos (72\%) preferiu não informar sua raça/cor. Quanto à cor da pele, 1.008 .044 (65,0\%) se declararam brancos, 388.209 (25,0\%) pardos, 107.969 (7\%) negros, 37.708 (2,5\%) amarelos e $7.573(0,5 \%)$ indígenas. O percentual de raças não brancas foi maior nas IES públicas, especialmente no caso da raça negra, que constituiu 10,9\% dos estudantes nas instituições públicas e 5,3\% nas particulares. Os autodeclarados brancos, por sua vez, representaram 58,0\% dos estudantes nas públicas e 68,0\% nas privadas. Um dado curioso é a grande diferença entre o número de alunos que se declarou portador de deficiência (19.517) e os que disseram ter ingressado por meio de cotas específicas para este grupo (122.385). Apenas 13.339 (0,2\%) se declararam estrangeiros.

Em relação às formas de ingresso na IES, 4.542 .392 (81,4\%) estudantes disseram ter passado por algum tipo de vestibular, um número relativamente alto comparado aos 431.257 (7,7\%) que entraram pelo Exame Nacional do Ensino Médio (Enem). É provável que essa proporção mude nos censos posteriores, visto que desde 2009 muitas universidades começaram a utilizar o Enem como forma de ingresso. A maioria das matrículas correspondeu a cursos de bacharelado (63,7\%), o nível predominante foi o de graduação $(99,4 \%)$ e a modalidade presencial representou $85,0 \%$ do total.

\section{Correlações}

A variável "ingressou por cota" apresentou correlação apenas com "recebeu financiamento não reembolsável" ( $r=0,55)$ e com "beneficiou-se com o ProUni" ( $r=0,75)$, sugerindo que as IES estão, em geral, articulando as cotas e o financiamento em políticas afirmativas mais amplas provavelmente em virtude da estrutura do ProUni.

Analisando cada tipo de cota (Tabela 2), a variável do ProUni apresentou correlação significativa ( $p<0,001$ ) com as cotas para escola pública $(r=0,86)$ e também com as étnicas $(r=0,54)$. O financiamento não reembolsável, por sua vez, estava mais amplamente correlacionado com: cotas para deficientes $(r=0,32)$; cotas de escola pública $(r=0,44)$; e cotas étnicas $(r=0,28)$. Esses dados reforçam a ideia anterior, sugerindo adicionalmente que as cotas para escola pública costumam estar mais vinculadas às políticas de financiamento dos que a outros tipos. Contrastando com esses resultados, que apontam na direção de uma política articulada de inclusão (reunindo cotas e financiamento), as cotas socioeconômicas só apresentaram correlação com o financiamento remunerado $(r=0,39)$ sugerindo, talvez, um desenho inadequado (enquanto ação afirmativa) das IES para esse tipo de cota. Por fim, cabe destacar a correlação entre cotas 
étnicas e atividades de extensão $(r=0,11)$ que, embora relativamente fraca, foi a única encontrada entre cotas e atividades extracurriculares, o que talvez indique que os cotistas tenham uma tendência maior a realizar atividades universitárias voltadas para a sociedade.

\section{Ações afirmativas}

Ao todo, 1.002.232 alunos (18,0\%) declararam receber financiamentos não reembolsáveis. Entre estes, 308.550 (5,5\%) referem-se ao ProUni, onde 235.049 (4,2\%) são de financiamento integral e 94.890 (1,7\%) parcial - sendo que $21.389(0,4 \%)$ incluem os dois tipos. O financiamento reembolsável atingiu apenas 65.346 (1,2\%) alunos, além disso, 327.598 (5,9\%) estudantes declararam receber algum tipo de apoio social.

As cotas, por sua vez, cobriram um total de 524.341 (9,4\%) das matrículas. Nas instituições públicas, 6,1\% dos alunos se declararam cotistas, e, nas privadas, $10,5 \%$. A maior porcentagem dentro das públicas foi nas estaduais $(8,1 \%)$, enquanto entre as privadas, as confessionais apresentaram a maior proporção de alunos cotistas (12,3\%). Na Tabela 2 podemos ver mais detalhes dos tipos de cota em cada categoria administrativa.

\section{Tabela 2 - Número de Cotistas Autodeclarados segundo Tipo de Cota e Categoria Administrativa}

\begin{tabular}{|c|c|c|c|c|c|c|c|c|}
\hline $\begin{array}{l}\text { Categoria adm./ } \\
\text { Tipo de cota }\end{array}$ & $\begin{array}{l}\text { Pública } \\
\text { federal }\end{array}$ & $\begin{array}{l}\text { Pública } \\
\text { estadual }\end{array}$ & $\begin{array}{l}\text { Pública } \\
\text { municipal }\end{array}$ & $\begin{array}{l}\text { Privada } \\
\text { particular }\end{array}$ & $\begin{array}{c}\text { Privada } \\
\text { confessional }\end{array}$ & $\begin{array}{c}\text { Privada } \\
\text { comunitária }\end{array}$ & Total & $\begin{array}{c}\text { Total } \\
\text { por } \\
\text { tipo } \\
(\%)\end{array}$ \\
\hline Escola pública & 0 & 0 & 754 & 173.834 & 40.183 & 20.278 & 235.049 & 50,01 \\
\hline Étnica & 0 & 0 & 128 & 79.787 & 10.597 & 4.378 & 94.890 & 20,19 \\
\hline Deficientes & 0 & 0 & 0 & 90.307 & 25.504 & 6.574 & 122.385 & 26,04 \\
\hline Socioeconômica & 0 & 242 & 229 & 7.769 & 503 & 1.517 & 10.260 & 2,18 \\
\hline Outros & 0 & 2 & 590 & 6.742 & 117 & 3 & 7.454 & 1,59 \\
\hline Todas $^{(1)}$ & 39.242 & 41.820 & 2.465 & 332.980 & 75.850 & 31.984 & 524.341 & \\
\hline
\end{tabular}

Fonte: Censo da Educação Superior (CES) 2009/Inep.

Nota: (1)Esta linha não corresponde à soma das anteriores, mas representa o número total de cotistas.

A Tabela 2 mostra que as cotas para egressos de escolas públicas se tornaram predominantes em todos os tipos de IES, correspondendo à metade do total. As cotas para portadores de deficiência e as cotas étnicas, por sua vez, ocupam respectivamente o segundo e terceiro lugares em todos os tipos de IES (com exceção das públicas municipais). Nota-se, também, que as IES públicas estaduais e federais não forneceram dados detalhados sobre tipos de cota, fato que ainda carece de explicação. Dada essa limitação, as análises utilizaram apenas o total de cotas, que corresponde à última linha da Tabela 2 (para mais detalhes, ver a variável "ingresso por cota" no script mencionado na metodologia).

Antes, porém, de analisar as cotas em geral, convém destacar alguns dados. A Tabela 2 fornece os números absolutos, mas não uma ideia 
adequada da porcentagem de cada tipo de cota nas diferentes categorias administrativas. Em relação às cotas para portadores de deficiência, as privadas confessionais apresentaram a maior taxa $(4,1 \%)$. Nas cotas étnicas, as privadas particulares tiveram o maior índice $(2,4 \%)$, enquanto as cotas para escola pública representaram a fatia máxima dos estudantes nas IES privadas comunitárias (6,9\%) e, logo abaixo, nas confessionais (6,5\%). Embora a diferença (dentro de cada tipo de cota) seja pequena, talvez esses dados indiquem certo padrão de conexão entre os três tipos mais frequentes de cota e os três tipos de IES privada. Trata-se, evidentemente, de mera especulação, uma hipótese que pode ser testada com dados de censos posteriores e outras fontes.

\section{Atividades extracurriculares}

O teste de hipótese realizado neste trabalho pressupõe que as atividades extracurriculares são indicadores indiretos da inclusão dos estudantes nas IES. Um resumo das atividades extracurriculares, de acordo com o Censo 2009, está reproduzido na Tabela 3.

\section{Tabela 3 - Alunos que Declararam ter Realizado Atividades Extracurriculares nas IES}

\begin{tabular}{|l|r|r|}
\hline \multicolumn{1}{|c|}{ Tipo de atividade } & Número absoluto & \% dos alunos \\
\hline Pesquisa remunerada & 44.765 & 0,8 \\
\hline Pesquisa não remunerada & 82.202 & 1,5 \\
\hline Extensão remunerada & 22.902 & 0,4 \\
\hline Extensão não remunerada & 407.412 & 7,3 \\
\hline Monitoria remunerada & 30.784 & 0,6 \\
\hline Monitoria não remunerada & 44.929 & 0,8 \\
\hline Estágio não obrigatório remunerado & 116.901 & 2,1 \\
\hline Estágio não obrigatório não remunerado & 74.984 & 1,3 \\
\hline
\end{tabular}

Fonte: Censo da Educação Superior (CES) 2009/Inep.

A maioria das atividades extracurriculares é de extensão não remunerada, enquanto o menor percentual é do mesmo tipo, porém, com remuneração (o que poderia, talvez, ser interpretado como um consenso implícito de que a extensão é importante, mas não precisa necessariamente ser paga). Mais uma vez, trata-se de mera especulação. O estágio não obrigatório remunerado foi a segunda atividade mais frequente, o que poderia estar relacionado a bolsas de iniciação científica e a benefícios semelhantes. Com exceção do estágio não obrigatório, as atividades não remuneradas superaram as atividades remuneradas dentro de cada tipo.

Para a realização da análise, agrupamos os oito tipos de atividades da Tabela 3 em sete variáveis resposta: uma correspondendo ao total de atividades; duas relativas à remuneração; e quatro para cada tipo de atividade extracurricular. A Tabela 4 mostra estas sete variáveis nas linhas, informando a média de atividades por aluno nas categorias administrativas. 


\section{Tabela 4 - Média de Atividades Extracurriculares por Aluno em cada Categoria Administrativa}

\begin{tabular}{|c|c|c|c|c|c|c|c|}
\hline \multirow{2}{*}{$\begin{array}{c}\text { Atividade } \\
\text { extracurricular }\end{array}$} & \multicolumn{7}{|c|}{ Categoria administrativa } \\
\hline & $\begin{array}{l}\text { Pública } \\
\text { federal }\end{array}$ & $\begin{array}{l}\text { Pública } \\
\text { estadual }\end{array}$ & $\begin{array}{l}\text { Pública } \\
\text { municipal }\end{array}$ & $\begin{array}{l}\text { Privada } \\
\text { particular }\end{array}$ & $\begin{array}{c}\text { Privada } \\
\text { confessional }\end{array}$ & $\begin{array}{c}\text { Privada } \\
\text { comunitária }\end{array}$ & Todas \\
\hline Remunerada & 0,058 & 0,044 & 0,059 & 0,024 & 0,081 & 0,048 & 0,035 \\
\hline $\begin{array}{l}\text { Não } \\
\text { remunerada }\end{array}$ & 0,024 & 0,068 & 0,240 & 0,124 & 0,097 & 0,202 & 0,088 \\
\hline Estágio & 0,018 & 0,023 & 0,056 & 0,029 & 0,067 & 0,081 & 0,034 \\
\hline Pesquisa & 0,029 & 0,040 & 0,021 & 0,020 & 0,017 & 0,023 & 0,022 \\
\hline Extensão & 0,015 & 0,034 & 0,213 & 0,088 & 0,082 & 0,134 & 0,077 \\
\hline Monitoria & 0,020 & 0,016 & 0,009 & 0,012 & 0,012 & 0,010 & 0,013 \\
\hline Todas & 0,083 & 0,113 & 0,299 & 0,148 & 0,178 & 0,250 & 0,118 \\
\hline
\end{tabular}

Fonte: Censo da Educação Superior (CES) 2009/Inep.

A Tabela 4 revela que as IES privadas confessionais apresentaram a maior proporção de atividades remuneradas por aluno, enquanto as privadas particulares são as que menos remuneram seus estudantes. Os estágios, por sua vez, foram proporcionalmente mais frequentes nas privadas comunitárias, enquanto as atividades de pesquisa e a monitoria foram mais comuns nas IES públicas federais e estaduais. Notamos também certa semelhança entre as instituições públicas municipais e as privadas comunitárias no que se refere à alta proporção de alunos que realizam atividades de extensão não remunerada.

De maneira geral, podemos dizer que embora as IES privadas particulares sejam responsáveis pela grande maioria de matrículas, em termos proporcionais elas parecem não estimular a realização de atividades extracurriculares, com exceção da extensão não remunerada.

\section{Cotistas e não cotistas ao longo dos anos}

Conforme descrito na seção de metodologia, para testar a hipótese de inclusão com qualidade, os registros foram agrupados segundo o ano de matrícula - lembrando que foram incluídas apenas as matrículas a partir de 2005, ano de início das políticas de cotas no Brasil. Dos alunos que responderam ao CES de 2009, 1.733.156 declararam ser ingressantes; 1.425.326, que estavam no $2^{\circ}$ ano; 1.133 .794 , no $3^{\circ} ; 822.443$, no $4^{\circ}$ ano; e 464.687, que se matricularam em 2005. A proporção de cotistas entre calouros e veteranos (separando, na verdade, em cinco faixas: de zero a quatro anos completos) foi relativamente estável, variando entre 8,8\% e 10,9\% do total de alunos em cada faixa. Com isso, torna-se possível comparar os cotistas e não cotistas ao longo dos anos na universidade. A média de atividades extracurriculares por aluno (Figura 1) corresponde à mesma variável da última linha da Tabela 4, só que agora dividida pelos anos em que o aluno está na IES. 


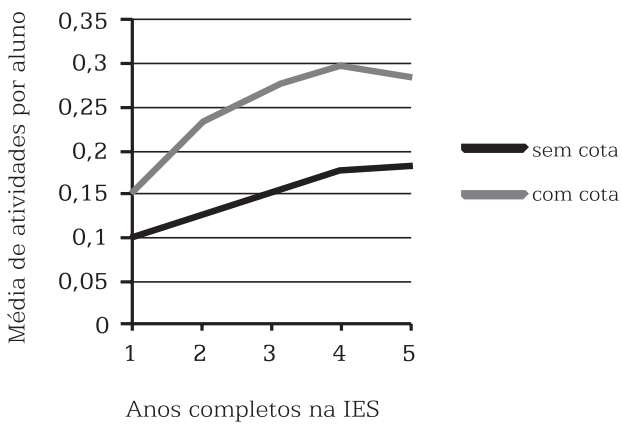

Figura 1 - Média de Atividades Extracurriculares dos Cotistas e não Cotistas ao longo dos Anos dentro da IES

Fonte: Censo da Educação Superior (CES) 2009/Inep.

Os cotistas realizaram, em média, mais atividades do que os outros e tal disparidade aumenta a cada ano. Seria possível argumentar que o aumento da diferença entre as médias ao longo dos anos esteja distorcido em virtude do caráter cumulativo da variável, ou seja, pode ser que os alunos com 3 anos completos às vezes respondam no questionário as atividades que já realizaram durante toda a vida acadêmica ao invés de colocarem apenas as relativas ao ano do censo. No entanto, a diminuição observada entre os cotistas, com três e quatro anos completos na IES, contraria esse argumento. Adicionalmente, o grande número de dados de estudantes utilizado neste estudo permite afirmar que os cotistas tendem a acumular mais atividades extracurriculares do que o restante dos alunos ao longo dos anos (Figura 1). A média dos veteranos cotistas ( $\mathrm{X}=0,28$ atividades extracurriculares por ano) foi significativamente maior $(\mathrm{W}=$ 234559775798 e $\mathrm{p}<2,2$ e-16) que a dos veteranos não cotistas ( $\mathrm{X}=$ 0,17 atividades extracurriculares por ano). Em que medida este padrão se repete quando consideramos os indicadores mais específicos de atividade extracurricular? A Figura 2 mostra as médias de atividades extracurriculares em dois subgrupos, separados pelo critério da remuneração.

Atividades não remuneradas

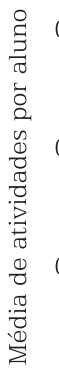

0,05

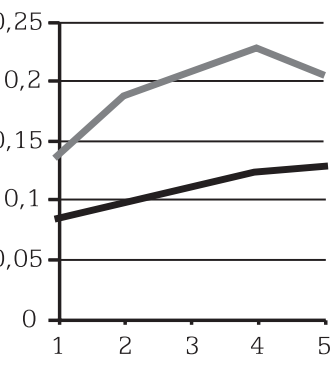

Anos completos na IES

\section{Atividades remuneradas}
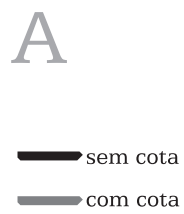

Figura 2 - Média de Atividades Extracurriculares Remuneradas e não Remuneradas de Cotistas e não Cotistas ao longo dos Anos dentro da IES

Fonte: Censo da Educação Superior (CES) 2009/Inep 
Além de serem menos frequentes, as atividades remuneradas começam igualmente distribuídas entre cotistas e não cotistas, mas ao longo dos anos a diferença entre eles vai aumentando. Por outro lado, nas atividades não remuneradas, os cotistas já se destacam do restante da população desde o primeiro ano na IES. É razoável supor que existam múltiplas interpretações para tais resultados e que em todas seja necessário recorrer a outras fontes de informação para garantir um mínimo de consistência. No entanto, isso não impede que sejam formuladas algumas hipóteses para explicar os padrões observados.

Partindo do pressuposto de que as atividades remuneradas tendem a ser mais criteriosas e seletivas do que as não remuneradas, é possível explicar porque o Gráfico A já começa com uma grande diferença entre cotistas e não cotistas, enquanto no Gráfico B ambos os grupos iniciam juntos, mas vão se diferenciando ao longo do tempo. A explicação seria justamente a hipótese de que os cotistas tendem a melhorar mais rápido do que os outros estudantes, o que seria mais evidente em contextos seletivos. Assim, a divisão em subgrupos, segundo a remuneração, forneceria uma confirmação adicional da hipótese de inclusão com qualidade. Seguindo esse raciocínio, é possível desqualificar as informações do Gráfico A, pois as atividades não remuneradas seriam consideradas sem muito critério - é uma possibilidade. Outra possibilidade é a de que a grande diferença entre cotistas e não cotistas nas atividades sem remuneração seja resultado da efetiva inclusão de uma nova população no ensino superior, talvez mais disposta a se integrar na vida acadêmica do que o restante, supostamente mais acostumado a este meio. De qualquer forma, os testes de significância anteriores para estes dois novos conjuntos de dados da Figura 2 também foram significativos $(p<2,2$ e-16).

Um segundo critério para a divisão dos dados em subgrupos é a natureza da atividade extracurricular. Divididos dessa forma, os dados da Figura 1 se separam nos quatro gráficos da Figura 3, cada qual correspondendo a um tipo de atividade extracurricular, independentemente da remuneração.

Nota-se na Figura 3 que as atividades de extensão (C) seguem um padrão semelhante ao das não remuneradas (Gráfico A da Figura 2), o que provavelmente decorre da prevalência de atividades desse tipo, como visto na Tabela 3. Observa-se também que os gráficos A, B e D apresentam certa semelhança, sendo que em A e B nota-se um padrão mais próximo ao das atividades remuneradas (Gráfico B da Figura 2), onde a diferença entre cotistas e não cotistas começa pequena e termina grande. Os testes de significância, realizados de forma independente para cada um dos quatro tipos de atividade, confirmaram que a média dos cotistas foi maior que a dos não cotistas depois de dois anos na IES $(\mathrm{p}<2,2$ e-16). 
A

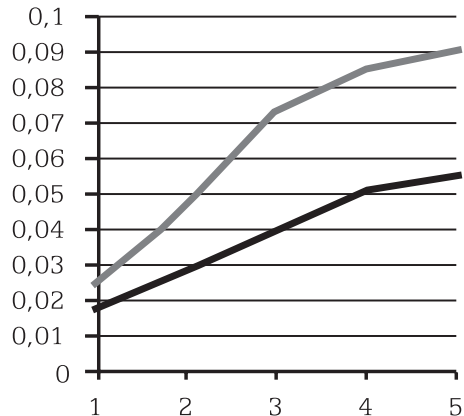

Anos completos na IES

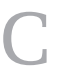

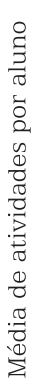

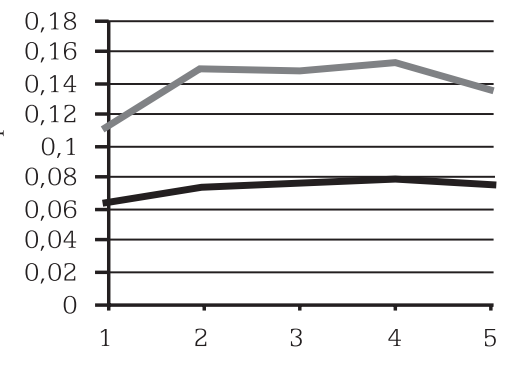

Anos completos na IES
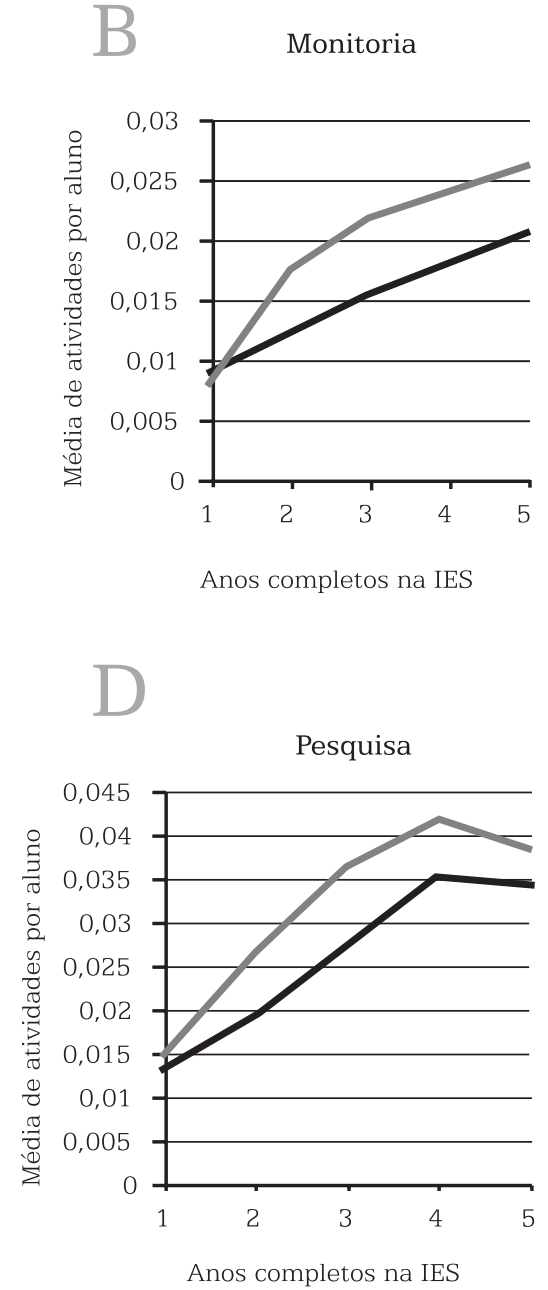

sem cota

com cota

Figura 3 - Média de cada tipo de Atividade Extracurricular de Cotistas e não Cotistas ao longo dos Anos dentro da IES

Fonte: Censo da Educação Superior (CES) 2009/Inep.

\section{Conclusão}

A análise do CES de 2009 mostra que depois de dois anos dentro da universidade os autodeclarados cotistas realizam mais atividades extracurriculares do que alunos não cotistas. O padrão é consistente, sendo observado também quando se analisa separadamente cada tipo de atividade (monitoria, pesquisa, estágio e extensão), mesmo quando é considerada a divisão entre atividades remuneradas e não remuneradas. Isso poderia ser interpretado de diversas formas; talvez os cotistas estejam mais dispostos a se integrar na vida acadêmica, talvez sintam necessidade 
de formação complementar, mas essas são meras especulações. Dessa forma, tais resultados corroboram a hipótese da inclusão com qualidade em nível nacional e sugerem que os cotistas integram-se mais amplamente à vida acadêmica do que os não cotistas.

Se as atividades extracurriculares podem ser consideradas indicadoras de competência acadêmica, os resultados deste estudo confirmam a hipótese de que os cotistas apresentaram desempenho médio superior aos não cotistas. Esse pressuposto é validado pela análise do desempenho dos cotistas em atividades remuneradas, em geral mais seletivas em termos de habilidades requeridas. No entanto, a generalidade desta conclusão é restringida pela ausência de dados sobre desempenho acadêmico estrito, proveniente de notas de provas ou cursos.

Assim, os dados permitem afirmar que os cotistas tendem a integrar-se mais amplamente às atividades acadêmicas do que o restante da população, conforme revelado pela análise das atividades remuneradas de estágio e monitoria. Nas atividades de extensão e nas não remuneradas, por sua vez, a diferença entre cotistas e não cotistas já é grande logo no primeiro ano; mais uma vez, a interpretação desse resultado pode ser controversa, mas uma possibilidade é que os cotistas apresentem certa tendência a realizar atividades acadêmicas voltadas para a sociedade como forma de "contrapartida" pelo benefício recebido. Essa interpretação baseia-se na ideia de que os cotistas, uma população até então excluída do meio acadêmico, conheceriam melhor a necessidade de se construir pontes para ultrapassar a distância existente entre as IES e a realidade social. Assim sendo, é possível afirmar que os cotistas não apenas têm condições de se inserir adequadamente no meio acadêmico, mas também que eles estimulam as IES a se incluírem na sociedade por meio das atividades de extensão. Isso explicaria, por exemplo, porque foi encontrada correlação entre cotas étnicas e atividades de extensão.

Algumas ressalvas precisam ser feitas a respeito dos resultados obtidos neste estudo. Em primeiro lugar, os dados provém de questionários respondidos por alunos e, portanto, podem existir distorções e imprecisões; contudo, o tamanho da amostra ajuda a diminuir esse efeito. Em segundo lugar, o que as atividades extracurriculares de fato indicam? Esta pergunta pode gerar uma longa discussão. Para os propósitos deste trabalho, elas sugerem certo grau de inclusão efetiva do aluno na IES. Algumas atividades indicariam com mais acuidade a inclusão com qualidade, como as atividades remuneradas, por exemplo. Contudo, é importante ressaltar que não foram utilizados dados de desempenho acadêmico propriamente dito, porque eles não existem nacionalmente - a não ser em eventuais testes amostrais ou no antigo "Provão". Uma última observação a ser feita sobre as restrições da análise é que alguns resultados encontrados neste estudo são significativamente diferentes dos dados divulgados no Resumo Técnico (Brasil, Inep, 2010), como a porcentagem de cotas para deficientes. Tal diferença poderia ser explicada pela ausência desse tipo de informação nas instituições públicas e no arquivo de microdados disponível no portal do Inep, conforme registrado na Tabela 2. 
Em síntese, as atividades extracurriculares mapeadas pelo CES 2009 são proporcionalmente mais realizadas pelos cotistas do que pelos alunos não cotistas e observa-se também, ao longo dos anos, um aumento maior no número de atividades extracurriculares entre os cotistas. Tais resultados podem ser considerados, à primeira vista, uma evidência a favor do impacto positivo da política de cotas tal qual vem sendo implementada no Brasil. No entanto, uma conclusão mais consistente seria considerá-los uma evidência a favor da ação afirmativa de um modo geral - que pode ou não utilizar cotas - num país estruturalmente desigual como o Brasil. O estudo da Unicamp (Tessler, 2006) corrobora essa hipótese, chegando a resultados semelhantes em um sistema que articula certo modelo de prova, isenções de matrícula para pessoas de baixa renda e bônus na nota do vestibular - ao invés de se limitar a cotas predeterminadas. Assim, o debate sobre o melhor modelo a ser adotado por cada instituição continua em aberto e é de fundamental importância para que as ações afirmativas sejam mais efetivas na educação superior brasileira.

\section{Referências bibliográficas}

ALMQUIST, Zack W. US Census Spatial and Demographic Data in R: the UScensus 2000 Suite of Packages. Journal of Statistical Software, v. 37, n. 6, p. 1-31, 2010.

BRASIL. Lei no 10.558, de 13 de novembro de 2002. Cria o Programa Diversidade na Universidade, e dá outras providências. Disponível em: < http://www.planalto.gov.br/ccivil_03/Leis/2002/L10558.htm>. Acesso em: 21 mar. 2011.

. Decreto $n^{\circ}$ 4.876, de 12 de novembro de 2003. Dispõe sobre a análise, seleção e aprovação dos Projetos Inovadores de Cursos, financiamento e transferência de recursos, e concessão de bolsas de manutenção e de prêmios de que trata a Lei no 10.558. Disponível em: <https://www.planalto.gov.br/ccivil_03/decreto/2003/D4876.htm>. Acesso em: 21 mar. 2011.

BRASIL. Ministério da Educação (MEC), Assessoria de Comunicação Social (ACS). Instituições que já adotam o sistema de cotas. [2005]. Disponível em: <http://portal.mec.gov.br/arquivos/pdf/acs140705_ instituicoes.pdf $>$. Acesso em: 18 mar. 2011.

BRASIL. Instituto Nacional de Estudos e Pesquisas Educacionais Anísio Teixeira (Inep). Resumo técnico: Censo da Educação Superior (CES) de 2009. 2010. 
BRASIL. Instituto Nacional de Estudos e Pesquisas Educacionais Anísio Teixeira (Inep). Microdados para download. Disponível em: <http://www.inep.gov.br/basica/levantamentos/acessar.htm>. Acesso em: 1 fev. 2011.

CATANI, Afrânio Mendes; HEY, Ana Paula; GILIOLI, Renato de Sousa Porto. ProUni: democratização do acesso às instituições de ensino superior? Educar em Revista, Curitiba (PR), n. 28, p. 125-140, 2006.

CORBUCCI, Paulo Roberto. Financiamento e democratização do acesso à educação superior no Brasil: da deserção do Estado ao projeto de reforma. Educação \& Sociedade, Campinas, v. 25, n. 88, p. 677-701, Especial, 2004. Disponível em: <http://www.cedes.unicamp.br>.

GUARNIERI, Fernanda Vieira; MELO-SILVA, Lucy Leal. Ações afirmativas na educação superior: rumos da discussão nos últimos cinco anos. Psicologia \& Sociedade, USP, São Paulo, v. 19, n. 2, p. 70-78, 2007.

MAIO, Marco Chor; SANTOS, Ricardo Ventura. Política de cotas raciais, os "olhos da sociedade" e os usos da antropologia: o caso do vestibular da Universidade de Brasília (UnB). Horizontes Antropológicos, Porto Alegre, v. 11, n. 23, p. 181-214, 2005.

MOEHLECKE, Sabrina. Ação afirmativa: História e debates no Brasil. Cadernos de Pesquisa, Fundação Carlos Chagas, São Paulo, n. 117, p. 197-217, 2002.

NEVES, Clarissa Eckert Baeta; RAIZER, Leandro; FACHINETTO, Rochele Fellini. Acesso, expansão e equidade na educação superior: novos desafios para a política educacional brasileira. Sociologias, Porto Alegre, n. 17, p. 124-157, 2007. Disponível em: <http://www.ufrgs.br/ ifch/posgrad/sociologia/ppgs_rev.htm $>$.

SANTOS, Jocélio Teles dos; QUEIROZ, Delcele Mascarenhas. Vestibular com cotas: análise em uma instituição pública federal. Revista USP, v. 68, p. 58-75, 2005.

TESSLER, Leandro R. Ação afirmativa sem cotas: o Programa de Ação Afirmativa e Inclusão Social (Paais) da Unicamp. Texto preparado para a mesa redonda "Experiências brasileiras: construção de alternativas II", no Simpósio Universidade e Inclusão Social - Experiência e Imaginação, realizado na Universidade Federal de Minas Gerais, de 22 a 24 de novembro de 2006. Disponível em: < http://www.comvest.unicamp.br/ paais/artigos.html>. 
UNIVERSIDADE ESTADUAL DO RIO DE JANEIRO (Uerj)/Laboratório de Políticas Públicas (LPP). Mapa das ações afirmativas. Disponível em: <http://www1.folha.uol.com.br/folha/educacao/ult305u361070.shtml>.

Rodrigo Travitzki é doutorando em Educação e Filosofia na Faculdade de Educação da Universidade de São Paulo (USP). travitzki@usp.br

Rafael Luís Galdini Raimundo é doutorando em Ecologia Evolutiva no Instituto de Biociências da Universidade de São Paulo (USP). rafael.raimundo@usp.br

Recebido em 20 de abril de 2011.

Aprovado em 21 de dezembro de 2011. 